\title{
A Case of Follicular Lymphoma Associated with Paraneoplastic Cerebellar Degeneration
}

\author{
Yayoi Shimazu ${ }^{1}$, Eiko N. Minakawa ${ }^{2}$, Momoko Nishikori ${ }^{1}$, Masafumi Ihara ${ }^{2}$, \\ Yuichiro Hashi ${ }^{2}$, Hirofumi Matsuyama ${ }^{2}$, Masakatsu Hishizawa ${ }^{1}$, Sonoyo Yoshida ${ }^{3}$, \\ Toshiyuki Kitano ${ }^{1}$, Tadakazu Kondo ${ }^{1}$, Takayuki Ishikawa ${ }^{1}$, \\ Ryosuke Takahashi $^{2}$ and Akifumi Takaori-Kondo ${ }^{1}$
}

\begin{abstract}
Paraneoplastic neurological disorders (PND) are neurological effects of malignancy that are recognized as immune-mediated disorders caused by aberrant expression of a tumor antigen that is normally expressed in the nervous system. We report a case of cerebellar ataxia which turned out to be paraneoplastic cerebellar degeneration, a subtype of PND that develops cerebellar symptoms, that was caused by follicular lymphoma. After chemotherapy, the patient attained sufficient improvement of cerebellar symptoms along with complete remission of lymphoma. Paraneoplastic cerebellar degeneration should be recognized as a rare complication of lymphoma as it is important to start proper treatment before the neurological symptoms become irreversible.
\end{abstract}

Key words: follicular lymphoma, paraneoplastic neurological disorders, paraneoplastic cerebellar degeneration

(Intern Med 51: 1387-1392, 2012)

(DOI: 10.2169/internalmedicine.51.7019)

\section{Introduction}

Patients with malignant tumors occasionally suffer from neurological complications due to various causes: direct invasion of the tumor into the nervous system, infections, coagulopathy, or side effects of chemotherapy or irradiation. Paraneoplastic neurological disorders (PND) are rare neurological complications that cannot be explained by these readily identifiable causes. Along with the discovery of several onconeural antibodies, PND are currently recognized as immune-mediated disorders that are triggered by aberrant expression in the tumor of an antigen that is normally expressed only in the nervous system. It can affect any part of the nervous system, such as the brain, cranial nerves, retina, spinal cord, neuromuscular junctions, peripheral nerves or muscles.

Paraneoplastic cerebellar degeneration is a classic type of
PND which demonstrates a range of cerebellar symptoms. It typically begins with gait ataxia and, over a few weeks or months, progresses to severe symmetrical truncal and limb ataxia with dysarthria and often nystagmus (1). This pancerebellar dysfunction is attributed to an extensive loss of Purkinje neurons (2), and whereas it initially does not show abnormal findings in radiological studies, it may advance to cerebellar atrophy in the later stages. This rare complication is mostly observed in patients with small cell lung cancer, gynecological and breast tumors and Hodgkin lymphoma (HL), and these malignancies were reported to comprise more than $90 \%$ of cases with paraneoplastic cerebellar degeneration in whom malignancies were proved (3).

We report here a patient with subacute cerebellar ataxia which turned out to be paraneoplastic cerebellar degeneration caused by follicular lymphoma (FL). The neurological symptoms had progressed for 4 months until the diagnosis was made, and he was bed-ridden when CHOP-like chemo-

${ }^{1}$ Department of Hematology and Oncology, Graduate School of Medicine, Kyoto University, Japan, ${ }^{2}$ Department of Neurology, Graduate School of Medicine, Kyoto University, Japan and ${ }^{3}$ Takashima General Hospital, Japan

Received for publication November 28, 2011; Accepted for publication February 6, 2012

Correspondence to Dr. Momoko Nishikori, nishikor@kuhp.kyoto-u.ac.jp 
A

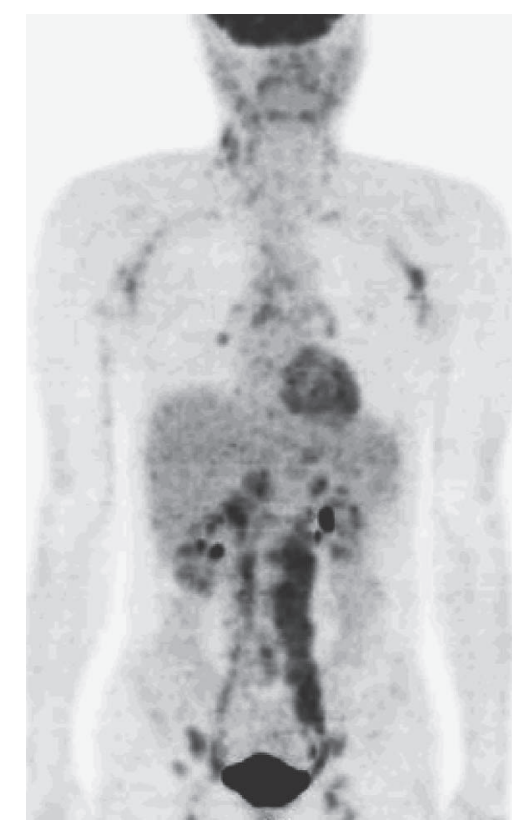

B

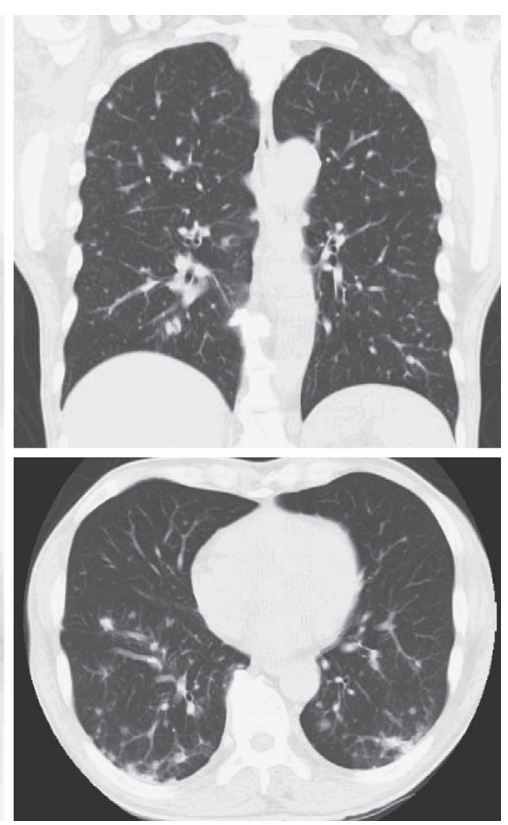

Figure 1. A. FDG-PET scan showing FDG uptake in the right cervical, bilateral axillar and hilar, mediastinal, paraaortic and bilateral inguinal lymph nodes. B. Chest CT scan demonstrating diffuse small nodular and reticular shadows, which turned out to be lymphoma lesions.

therapy with rituximab was started. However, both his neurological symptoms and lymphoma responded well to immunochemotherapy, and he finally attained adequate improvement in neurological symptoms along with complete remission of lymphoma. To our knowledge, there is no previous report of paraneoplastic cerebellar degeneration associated with non-Hodgkin lymphoma (NHL) that almost completely resolved after anti-tumor therapy. Recent understanding of the pathogenesis of PND and its rare combination with NHL are discussed.

\section{Case Report}

A 55-year-old man with no previous disease history presented with progressive gait ataxia lasting for 3 months. He had a history of smoking 30 cigarettes /day for 20 years until he quit 15 years earlier. He had been an occasional drinker with no history of alcohol abuse. He was working as a tile craftsman but became unable to work because of his neurological symptoms. He visited a clinic 1 month after ataxia appeared. He was examined by brain magnetic resonance imaging (MRI), brain perfusion scintigraphy and cerebrospinal fluid examination, but no abnormal findings were observed. His ataxic gait gradually progressed, and he was referred to our hospital.

There were no specific physical findings other than cerebellar signs such as fixation nystagmus, dysarthria and limb ataxia with a wide-based gait. His muscle strength, sensation and deep tendon reflexes were intact on all extremities. According to the Scale for the Assessment and Rating of Ataxia (SARA) for the evaluation of cerebellar ataxia sever- ity (4), his ataxic symptoms were scored as 30 . His laboratory screening did not show any abnormal findings, and serological tests for HIV, HTLV-1, HBV, HCV, VDRL and auto-antibodies were also negative. Cerebrospinal fluid analysis revealed a leukocyte count of $7 / \mathrm{mm}^{3}, 63 \mathrm{mg} / \mathrm{dL}$ glucose (normal range $40-80 \mathrm{mg} / \mathrm{dL}$ ), $20.5 \mathrm{mg} / \mathrm{dL}$ total protein (normal range 15-45 mg/dL) and $1.9 \mathrm{mg} / \mathrm{dL} \mathrm{IgG} \mathrm{(nor-}$ mal range 1.0-3.0 mg/dL), and was negative for neoplastic cells, bacteria, fungi or viruses in pathological and microbiological examinations. MRI of the brain suggested only mild cerebellar atrophy, and that of the cervical spine did not show abnormal findings. N-isopropyl-p- ${ }^{123} \mathrm{I}$-iodo amphetamine ( ${ }^{123} \mathrm{I}$-IMP) single-photon emission computed tomography (SPECT) showed no reduction in cerebellar perfusion. Primary cerebellar diseases such as acute cerebellar ataxia or classical cerebellar degenerative disorders were considered unlikely due to the subacute progressive course over months and no specific findings on these imaging tests or cerebrospinal fluid analysis. His neurological symptoms were suspected to have occurred secondarily to other systemic conditions; therefore, paraneoplastic neurological syndrome was considered.

Cervical and inguinal lymph node swelling was noticed at that time, and a whole body computed tomography (CT) scan demonstrated systemic lymphadenopathy. ${ }^{18}$ F-Fluoro-2deoxy-D-glucose positron emission tomography (FDG-PET) scanning revealed FDG uptake in these lymph nodes (Fig. 1A), and malignant lymphoma was predominantly suspected. Tumor marker screening showed increased levels of soluble interleukin-2 receptor (sIL-2R) to $2,270 \mathrm{U} / \mathrm{mL}$ (normal range $145-519 \mathrm{U} / \mathrm{mL}$ ) and prostate specific antigen 
Table 1. Previously Reported Paraneoplastic Antibodies

\begin{tabular}{lll}
\hline Antibody & Present case & Associated neoplasms \\
\hline anti-Tr & - & Hodgkin lymphoma \\
anti-Yo & - & Ovarian cancer \\
& & Breast cancer \\
anti-Hu & - & Small cell lung cancer \\
& & Prostate cancer \\
anti-Ri & - & Breast cancer \\
& & Small cell lung cancer \\
anti-MA1 & - & Lung cancer \\
anti-MA2 & - & Testicular cancer \\
anti-CV2 & - & Small cell lung cancer \\
& - & Thymoma \\
anti-mGluR1 & - & Hodgkin lymphoma \\
anti-amphiphysin & - & Breast cancer \\
& & Small cell lung cancer \\
\hline
\end{tabular}

(PSA) to $5.63 \mathrm{ng} / \mathrm{mL}$ (normal $<4.0 \mathrm{ng} / \mathrm{mL}$ ). A pelvic MRI was performed to check for prostate cancer, but no specific findings were detected in the prostate. Biopsy of the right cervical lymph node led to a diagnosis of FL, grade 2 . Bone marrow examination demonstrated $19.2 \%$ lymphoma cells, and $I g H / B C L 2$ rearrangement was shown by karyotyping and fluorescence in situ hybridization analysis. He falls into the intermediate-risk group according to both the Follicular Lymphoma International Prognostic Index (FLIPI) and FLIPI $2(5,6)$. His neurological symptoms were assumed to be associated with FL, although there was no previous report of paraneoplastic cerebellar degeneration caused by FL. We carried out analysis for several known paraneoplastic antibodies in his serum but none of them were detected (Table 1).

By that time he presented several new findings: pathological cells appeared in his peripheral blood and rapidly increased to $16.0 \%\left(2.7 \times 10^{9} / \mu \mathrm{L}\right)$, and fever and dry cough developed along with $\mathrm{C}$-reactive protein (CRP) elevation to $15.1 \mathrm{mg} / \mathrm{dL}$ (normal $<0.2 \mathrm{mg} / \mathrm{dL}$ ). Reexamination of the chest CT scan revealed diffuse small nodular and reticular shadows in the bilateral lung with multiple lymphadenopathy (Fig. 1B). Cytological examination of the bronchoalveolar lavage fluid (BALF) showed $42 \%$ alveolar macrophages, $23 \%$ neutrophils, $3 \%$ eosinophils, and $21 \%$ lymphocytes, and flow cytometric analysis demonstrated that these lymphocytes were positive for CD19, CD20, Sm-IgM, Sm-א, and HLA-DR, which were the same phenotypes as the malignant cells observed in the lymph node and bone marrow. On the other hand, microbiological examinations of BALF did not show any positive findings. According to these results, the lung lesion was diagnosed as a rapid invasion of lymphoma, and his fever and CRP elevation were also considered as accompanying symptoms.

$\mathrm{He}$ received CHOP-like chemotherapy (cyclophosphamide, doxorubicin, and prednisolone) combined with rituximab. Vincristine was omitted to avoid further deteriora- tion of his neurological symptoms. After the first course of chemotherapy, pathological cells disappeared from his peripheral blood, and the CT scan showed disappearance of the lung lesion and a reduction in the size of the lymph nodes. Although he was bed-ridden when chemotherapy was started, his cerebellar ataxia showed gradual improvement with treatment, and after 3 courses of chemotherapy he could walk alone and was discharged from hospital (Fig. 2). Chemotherapy was continued for 6 courses, and he achieved complete remission of lymphoma at the end of the treatment. His neurological symptoms almost completely disappeared with slight residual dysarthria, and were scored as 1 at SARA. Fifteen months after the completion of chemotherapy FL recurred in his cervical lymph nodes, but a second remission was achieved with rituximab monotherapy and recurrence of cerebellar ataxia was successfully avoided.

\section{Discussion}

PND are a rare complication of malignancy which occur in less than about $0.01 \%$ of patients with cancer (7). Classical neurological symptoms include those that affect the central nervous system (ex. encephalomyelitis, limbic encephalitis, subacute cerebellar degeneration, opsoclonusmyoclonus), those that affect the peripheral nervous system (ex. subacute sensory neuronopathy, autonomic neuropathies), and those that affect neuromuscular junctions and muscles (ex. myasthenia gravis, Lambert-Eaton myasthenic syndrome or dermatomyositis) (8). PND often progress rapidly within several weeks to months and the patients become severely disabled and sometimes die. However, the tumors causing PND are often indolent and sometimes occult, and PND antedates the diagnosis of malignancy in almost $80 \%$ of cases. The tumors are histologically identical to those that develop in patients without PND, except that many tumors show evidence of immune infiltration (9).

Paraneoplastic cerebellar degeneration is a subtype of PND, and classically a severe pancerebellar syndrome develops within 12 weeks with no evidence of cerebellar atrophy. The present patient met the diagnostic criteria for definite PND, a classical subacute cerebellar degeneration with a tumor that develops within five years of the diagnosis of the neurological disorder (8). Improvement in neurological symptoms after chemotherapy also strongly supported the diagnosis of PND.

Although HL is one of the major malignancies that cause paraneoplastic cerebellar degeneration, there are only 8 cases of NHL, including the present case, that are reported to be associated with this neurological complication (10-16) (Table 2). The neurological symptoms partially improved in 2 , remained stable in 1 and deteriorated in 5 despite chemotherapy, and the present case is the only case that achieved almost complete resolution. Paraneoplastic cerebellar degeneration associated with HL is reported to show a male predominance with a younger age distribution compared to other solid tumors $(3,17,18)$, and this also seems to be the 


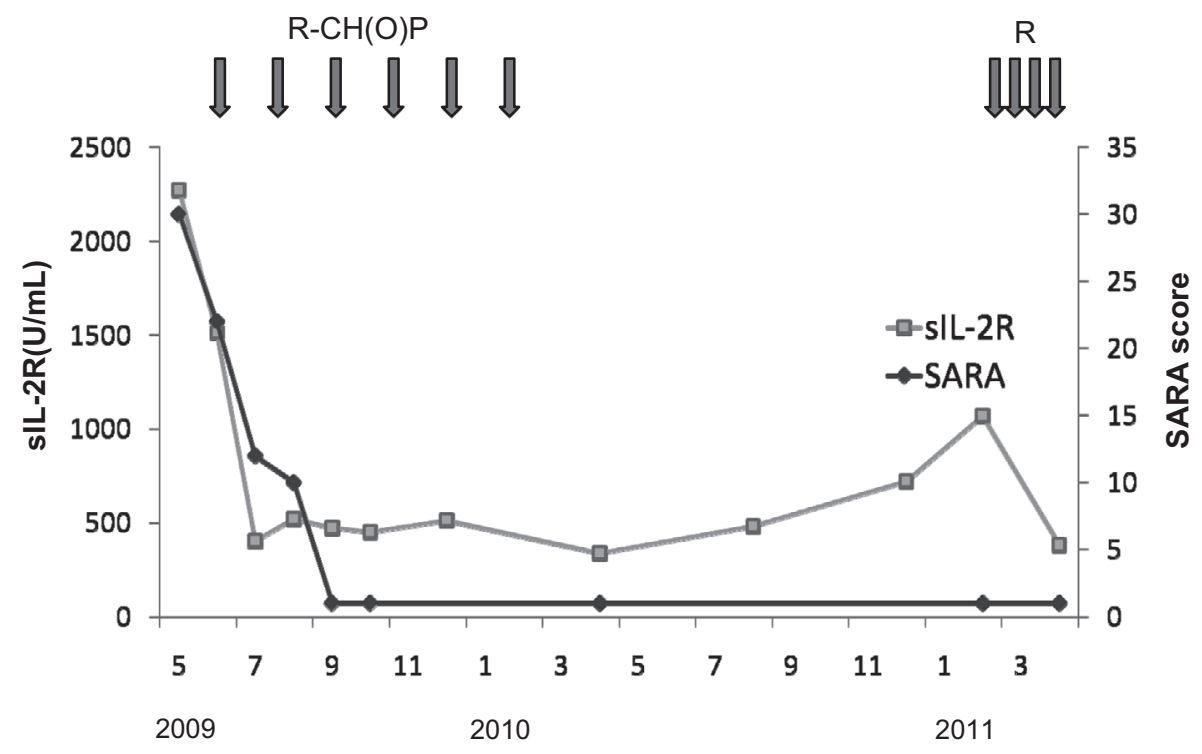

Figure 2. Clinical course of the patient.

Table 2. NHL Cases Associated with Paraneoplastic Cerebellar Degeneration

\begin{tabular}{|c|c|c|c|c|c|c|c|c|c|}
\hline Ref. & $\begin{array}{l}\text { Age } \\
\text { /Sex }\end{array}$ & Histology & Stage & Treatment & $\begin{array}{l}\text { PCD onset to } \\
\text { diagnosis of } \\
\text { lymphoma }\end{array}$ & $\begin{array}{l}\text { Clinical } \\
\text { outcome of } \\
\text { ataxia }\end{array}$ & $\begin{array}{l}\text { Clinical } \\
\text { outcome of } \\
\text { lymphoma }\end{array}$ & $\begin{array}{l}\text { Observation } \\
\text { period from } \\
\text { diagnosis }\end{array}$ & $\begin{array}{l}\text { Cause of } \\
\text { death }\end{array}$ \\
\hline [8] & $55 / \mathrm{F}$ & NHL & I & $\begin{array}{l}\text { Radiation } \\
\rightarrow \text { PSL }\end{array}$ & $-2 \mathrm{~m}$ & $\begin{array}{l}\text { Partially } \\
\text { improved }\end{array}$ & $\mathrm{CR}$ & $1 \mathrm{y}$ & Alive \\
\hline [9] & $72 / \mathrm{F}$ & NHL & $\begin{array}{l}\text { II, } \\
\text { relapse }\end{array}$ & COP & $-2 \mathrm{~m}$ & Stable & $\mathrm{CR}$ & $7 y$ & Alive \\
\hline$[10]$ & $53 / \mathrm{M}$ & T-NHL & IV & $\mathrm{COP}$ & $2.2 \mathrm{w}$ & Worsen & $\mathrm{PD}$ & $10 \mathrm{~d}$ & Oncological \\
\hline$[11]$ & $42 / \mathrm{M}$ & T-NHL & III & $\mathrm{ACOMPB}^{* 1}$ & $0.2 \mathrm{w}$ & Worsen & $\mathrm{CR}$ & $6.5 \mathrm{y}$ & Neurological \\
\hline [12] & $28 / \mathrm{M}$ & ALCL & III & $\mathrm{CHOP}+\mathrm{PSL}$ & $3 \mathrm{w}$ & Worsen & $\mathrm{CR}$ & $9 \mathrm{~m}$ & Oncological \\
\hline$[13]$ & $47 / \mathrm{M}$ & $\begin{array}{l}\text { Composite } \\
\text { (HL+B-LPD) }\end{array}$ & II & $\begin{array}{l}\text { ABVD } \\
\text { Rituximab }\end{array}$ & $0.7 \mathrm{w}$ & $\begin{array}{l}\text { Partially } \\
\text { improved }\end{array}$ & $\mathrm{CR}$ & 1 y $6 \mathrm{~m}$ & Alive \\
\hline [14] & $68 / \mathrm{M}$ & DLBCL & NA & NA & $4 \mathrm{~m}$ & Worsen & NA & $1 \mathrm{y}$ & Neurological \\
\hline $\begin{array}{l}\text { Present } \\
\text { case }\end{array}$ & $55 / \mathrm{M}$ & FL & IV & $\mathrm{R}-\mathrm{CH}(\mathrm{O}) \mathrm{P}$ & $4 \mathrm{w}$ & $\begin{array}{l}\text { Almost } \\
\text { resolved }\end{array}$ & $\mathrm{CR}\left(2^{\text {nd }}\right)$ & $2 y$ & Alive \\
\hline
\end{tabular}

${ }^{* 1}$ A chemotherapeutic regimen containing doxorubicin, cyclophosphamide, vincristine, methotrexate, prednisolone and bleomycin.

ALCL: anaplastic large cell lymphoma, B-LPD: B-cell lymphoproliferative disorder, DLBCL: diffuse large B-cell lymphoma, NA: not available.

case with NHL.

Paraneoplastic disorders documented in FL patients are almost exclusively cases of pemphigus vulgaris, and there are few reports on FL that is associated with other paraneoplastic complications. The present patient had an atypical clinical FL course in that diffuse lung involvement rapidly developed without evidence of histological transformation. Expression of an unusual surface adhesion molecule on lymphoma cells may have triggered the appearance of rare neurological complications in this patient.

It is currently considered that most or all PND are immune-mediated disorders $(7,19)$. The mechanism is explained by the ectopic expression by a tumor of an antigen that is normally expressed exclusively in the nervous sys- tem. Several paraneoplastic antibodies are frequently associated with PND caused by specific tumors: anti-Hu in small cell lung cancer and prostate cancer, anti-CV2 in small cell lung cancer and thymoma, anti-amphiphysin and anti-Ri in breast and small cell lung cancers, anti-Yo in ovary and breast cancers, anti-MA1 in lung cancer, anti-MA2 in testicular cancer, and anti-Tr and anti-mGluR1 in HL. Among the reported NHL cases, the paraneoplastic antibody was identified in only 1 case of composite lymphoma. But as the antibody observed was anti-Tr, it may be more related to an HL component than to NHL, and it is not clear whether there are specific antibodies for PND associated with NHL. We examined the present patient's serum for anti-Tr, antiYo, anti-Hu, anti-Ri, anti-MA1, anti-MA2, anti-CV2, anti- 
mGluR1 and anti-amphiphysin antibodies, but they were all negative (Table 1). Although various paraneoplastic antibodies have been found, less than $50 \%$ of patients with PND were proven to harbor these known onconeural antibodies (8) and the absence of these antibodies does not rule out the diagnosis of PND.

Paraneoplastic antibodies are classified into two groups according to their pathogenetic mechanisms: those that target intracellular antigens that probably cause neuronal damage by cytotoxic $\mathrm{T}$ cells, or those react directly with neuronal cell-surface antigens $(20,21)$. The former antibodies include anti-Hu, anti CV2, anti-amphiphysin, anti-Ri, anti-Yo, and anti-MA2. PND associated with these antibodies are thought to be mediated by T-cell immune responses that are considered to be directed against the onconeural targets of the antibodies. The latter antibodies include those against voltage-gated potassium channels, N-methyl-D-aspartate (NMDA) receptor, metabotropic glutamate receptor type 1 (mGluR1) and P/Q type voltage-gated calcium channels. The T-cell mediated disease mechanisms of the former are difficult to treat with strategies directed at the humoral immune response. In contrast, the latter group shows a good response to immunotherapy, and the paraneoplastic antibody titers correlate well with neurological outcomes. Our case showed rapid improvement in neurological symptoms with chemotherapy and his disease may have been mediated by an antibody against neuronal surface antigen.

A relationship between onconeural antibodies and outcomes has also been reported. Survival was significantly better in the patients with anti-Tr (median $>113$ months) compared with those with anti-Yo (median 13 months) or anti-Hu (median 7 months), although anti-Tr is considered to be directed against intracellular antigens (3). Neurological disability is also reported to be less severe in those with anti-Tr and anti-mGluR1 than other types (3). In HL patients with anti-Tr and anti-mGluR1, disappearance of these antibodies from the serum is reported to predict clinical improvement $(3,18)$.

For most cases of PND of the central nervous system, therapy is difficult and must be started early to prevent progressive neuronal death $(1,22)$. The main treatment approach for PND is removal of the source of the antigen by treating the underlying tumor, and immunomodulatory therapies such as steroids, plasma exchange and intravenous immunoglobulin are also tried for refractory cases. If the disease is suspected to be mediated by $\mathrm{T}$ cells, immunosuppressive drugs such as tacrolimus or mycophenolate mofetil can be considered, but there is no adequate evidence that they improve the clinical course. Rituximab results in longlasting B-cell depletion, and is expected to reduce paraneoplastic antibodies. A clinical study of adding rituximab to the treatment of PND with anti-Hu or anti-Yo antibodies showed some improvement in a small number of patients (23), but it is not clear how much efficacy could be attributed to rituximab. In B-NHL cases, rituximab is included in the standard therapy, and it may be an advantage in the treatment of PND.

In NHL patients, many of the accompanying neurological complications are caused by compression or direct tumor invasion to the nervous system. However, PND including paraneoplastic cerebellar degeneration can rarely be a complication of NHL and the correct diagnosis is important for starting the appropriate treatment before the neurological symptoms become irreversible.

\section{The authors state that they have no Conflict of Interest (COI).}

\section{Acknowledgement}

We thank Prof. Ryuichi Shigemoto, Okazaki National Research Institutes, for his help in the evaluation of the antimGluR1 antibody in the patient's serum.

Yayoi Shimazu and Eiko N. Minakawa equally contributed to this work.

\section{References}

1. Vedeler CA, Antoine JC, Giometto B, et al. Management of paraneoplastic neurological syndromes: report of an EFNS Task Force. Eur J Neurol 13: 682-690, 2006.

2. Graus F, Dalmau J. Paraneoplastic neurological syndromes: diagnosis and treatment. Curr Opin Neurol 20: 732-737, 2007.

3. Shams'ili S, Grefkens J, de Leeuw B, et al. Paraneoplastic cerebellar degeneration associated with antineuronal antibodies: analysis of 50 patients. Brain 126: 1409-1418, 2003.

4. Schmitz-Hubsch T, du Montcel ST, Baliko L, et al. Scale for the assessment and rating of ataxia: development of a new clinical scale. Neurology 66: 1717-1720, 2006.

5. Solal-Celigny P, Roy P, Colombat $\mathrm{P}$, et al. Follicular lymphoma international prognostic index. Blood 104: 1258-1265, 2004.

6. Federico M, Bellei M, Marcheselli L, et al. Follicular lymphoma international prognostic index 2: a new prognostic index for follicular lymphoma developed by the international follicular lymphoma prognostic factor project. J Clin Oncol 27: 4555-4562, 2009.

7. Darnell RB, Posner JB. Paraneoplastic syndromes involving the nervous system. N Engl J Med 349: 1543-1554, 2003.

8. Graus F, Delattre JY, Antoine JC, et al. Recommended diagnostic criteria for paraneoplastic neurological syndromes. J Neurol Neurosurg Psychiatry 75: 1135-1140, 2004.

9. Albert ML, Darnell RB. Paraneoplastic neurological degenerations: keys to tumour immunity. Nat Rev Cancer 4: 36-44, 2004.

10. Clouston PD, Saper CB, Arbizu T, et al. Paraneoplastic cerebellar degeneration. III. Cerebellar degeneration, cancer, and the Lambert-Eaton myasthenic syndrome. Neurology 42: 1944-1950, 1992.

11. Symonds RP, Hogg RB, Bone I. Paraneoplastic neurological syndromes associated with lymphomas. Leuk Lymphoma 15: 487490, 1994.

12. Ang LC, Zochodne DW, Ebers GC, Kaufmann JC, Vinters HV. Severe cerebellar degeneration in a patient with T-cell lymphoma. Acta Neuropathol 69: 171-175, 1986.

13. Ishihara K, Suzuki Y, Shiota J, Kawamura M, Nakano I. An autopsied case of paraneoplastic neurologic syndrome (limbic encephalitis, cerebellar degeneration, and pseudohypertrophy in the inferior olivary nuclei) associated with $\mathrm{T}$ cell lymphoma. Rinsho Shinkeigaku 45: 583-589, 2005 (in Japanese, Abstract in English).

14. Rodis DG, Liatsos GD, Moulakakis A, Pirounaki M, Tasidou A. 
Paraneoplastic cerebellar degeneration: initial presentation in a patient with anaplastic T-cell lymphoma, associated with ichthyosiform cutaneous lesions. Leuk Lymphoma 50: 1369-1371, 2009.

15. Razzak A, Shields M, Allsup D. Autoimmune paraneoplastic cerebellar degeneration secondary to a composite lymphoma. Leuk Lymphoma 48: 1456-1458, 2007.

16. Tanaka K, Yamazaki M, Sato S, Toyoshima I, Yamamoto A, Miyatake T. Antibodies to brain proteins in paraneoplastic cerebellar degeneration. Neurology 36: 1169-1172, 1986.

17. Hammack J, Kotanides H, Rosenblum MK, Posner JB. Paraneoplastic cerebellar degeneration. II. Clinical and immunologic findings in 21 patients with Hodgkin's disease. Neurology 42: 19381943, 1992.

18. Bernal F, Shams'ili S, Rojas I, et al. Anti-Tr antibodies as markers of paraneoplastic cerebellar degeneration and Hodgkin's disease.
Neurology 60: 230-234, 2003.

19. Roberts WK, Darnell RB. Neuroimmunology of the paraneoplastic neurological degenerations. Curr Opin Immunol 16: 616-622, 2004.

20. Dalmau J, Rosenfeld MR. Paraneoplastic syndromes of the CNS. Lancet Neurol 7: 327-340, 2008.

21. Graus F, Saiz A, Dalmau J. Antibodies and neuronal autoimmune disorders of the CNS. J Neurol 257: 509-517, 2010.

22. Voltz R. Paraneoplastic neurological syndromes: an update on diagnosis, pathogenesis, and therapy. Lancet Neurol 1: 294-305, 2002.

23. Shams'ili S, de Beukelaar J, Gratama JW, et al. An uncontrolled trial of rituximab for antibody associated paraneoplastic neurological syndromes. J Neurol 253: 16-20, 2006.

\footnotetext{
(C) 2012 The Japanese Society of Internal Medicine http://www.naika.or.jp/imindex.html
} 